\title{
Relações entre biologia e educação física: o olhar de especialistas sobre uma proposta de sequência didática
}

\section{Relations between physical education and biology: specialists look over a proposed didactic sequence}

Fernanda Beraldo Lorena é licenciada e aluna do curso de Ciências Biológicas da Universidade Presbiteriana Mackenzie.

Contato: fee.lorena@gmail.com

Isabel Porto Filgueiras é professora do curso de Educação Física do Centro Ciências Biológicas e da Saúde (CCBS), da Universidade Presbiteriana Mackenzie.

\section{Contato: isabel.filgueiras@mackenzie.br}

Magda Medhat Pechliye é professora do curso de Ciências Biológicas do Centro de Ciências Biológicas e da Saúde (CCBS), da Universidade Presbiteriana Mackenzie.

Contato: pechliye@mackenzie.br

\section{Resumo}

A atual organização curricular de grande parte das escolas brasileiras apresenta-se de forma fragmentada e desconexa, o que limita o desenvolvimento global e integrado das competências e habilidades dos alunos. Os projetos e as sequências didáticas interdisciplinares surgem como uma opção para superar tal limitação, mas ainda existem poucos estudos que abordam experiências de integração curricular na escola. 0 objetivo deste trabalho foi elaborar, a partir do pressuposto teórico da interdisciplinaridade, uma sequência didática visando à integração das disciplinas de biologia e educação física a partir do tema fisiologia do exercício. 0 material foi então submetido à análise de especialistas 
de ambas as áreas a fim de avaliar a viabilidade de se realizar a proposta com alunos do ensino fundamental II. Os pareceres dos avaliadores indicaram aspectos positivos da sequência didática, tais como a diversidade e a criatividade das atividades, a preocupação com o levantamento de conhecimentos prévios e a contextualização dos conteúdos com a vida dos alunos, aspectos estes considerados importantes no processo de aprendizagem. Segundo eles, a sequência elaborada é passível de aplicação e compatível com os objetivos propostos, embora tenha sido ressaltada a dificuldade de encontrar uma escola com disponibilidade para o trabalho interdisciplinar proposto, devido à organização do horário dos professores e à atual fragmentação do currículo. Ainda, a sequência permite ao professor um exercício reflexivo, o que contribui para o aprimoramento de sua prática.

Palavras-chave: interdisciplinaridade; educação física escolar; ensino de biologia.

\section{Abstract}

The current curriculum of most of the Brazilian schools is presented in a fragmented and disjointed way, which limits the development of comprehensive and integrated skills and abilities of students. The didactic interdisciplinary projects and sequences appear as an option to overcome this limitation, but there are few studies that discuss the experiences of curriculum integration in school. The aim of this study was to determine, from the interdisciplinary theoretical assumption, a didactic sequence to integrate the disciplines biology and physical education from the subject exercise physiology. The material was then submitted to expert analysis of the two disciplines in order to evaluate the feasibility of the proposal with elementary school students. The opinions of the evaluators of both disciplines indicated that the didactic sequence had positive aspects, such as creativity and diversity of activities, concern for the lifting of prior knowledge and context of content to students' lives, aspects considered important in the learning process. The sequence drawn, according to the evaluators, is capable of application and compatible with its objectives, although it was emphasized the difficulty of finding a school with availability to perform interdisciplinary work 
as proposed, due to the organization of teachers' time and current curriculum fragmentation. The sequence also allows the teacher reflexive exercise, which contributes to the improvement of the practice.

Keywords: interdisciplinarity; school physical education; biology teaching.

\section{Introdução}

A fragimentação do conhecimento é muito presente nos processos de ensino e aprendizagem. Tal como é feita hoje, a organização curricular não beneficia o ensino de relações e os conteúdos acabam ficando soltos, de maneira que não fazem sentido para os alunos (ZABALA, 2002). A crítica à organização disciplinar do currículo e a busca de alternativas integradoras para diminuir o caráter fragmentado do trabalho escolar têm envolvido diversos autores ao longo da história recente (HERNÁNDEZ; VENTURA, 1998; ALVES, 2000; SÃO PAULO, 2007).

Documentos como os Parâmetros curriculares nacionais (BRASIL, 1998) e as Orientações curriculares da Prefeitura de São Paulo (2007) propõem que a organização curricular deve se basear no que cada área de conhecimento pode contribuir para a formação de alunos aptos a integrar conhecimentos a fim de solucionar problemas do cotidiano e perceber o mundo social. Nesse sentido, o planejamento coletivo e a experimentação de estratégias de integração curricular são ferramentas que possibilitam a formação de alunos capazes de se posicionar de maneira crítica, utilizar diferentes fontes de informação para a construção do conhecimento e questionar a realidade, formulando problemas e propondo hipóteses e soluções (ZABALA, 2002).

Zabala (1998), ao tratar desse assunto, introduz a ideia de métodos g'lobalizados, os quais são definidos como estratégias que não tomam as disciplinas como ponto de partida para a organização dos conteúdos, mas que circulam entre os conteúdos escolares sem perder a continuidade, buscando estabelecer vínculos entre os temas disciplinares. Dessa forma, o ensino passa a ter um enfoque globalizador em que o aluno é o protagonista, de modo que seus interesses, suas capacidades e suas motivações são levados em conta.

Hernández (1998) prefere adotar o conceito de projetos de trabalho. Tal metodologia tem como função favorecer a criação 
de estratégias de organização do conhecimento que facilitem a construção de significados e da subjetividade dos alunos, além da transformação da informação que os alunos carregam em si e levam para a sala de aula. Os projetos de trabalho estão vinculados a uma concepção de mudança em relação ao currículo disciplinar fragmentado e, para que essa mudança seja efetivada, é importante considerar a organização de um currículo mais integrado e não disciplinar. Também se deve levar em conta o papel do professor como facilitador da relação dos alunos com o conhecimento.

Segundo o autor, os projetos de trabalho permitem a solução de problemas reais, partindo de temas mais abrangentes que possibilitam o estabelecimento de relações e vínculos com ideias principais e metodologias de diferentes disciplinas (HERNÁNDEZ, 1998). Além disso, mostram um acompanhamento mais próximo do processo de aprendizagem por parte do professor e promovem um exercício reflexivo sobre a prática docente (HERNÁNDEZ; VENTURA, 1998).

Zabala (1998) inclui as sequências didáticas no conjunto dos métodos globalizados, desde que busquem uma modificação no panorama fragmentado dos currículos atuais. Nesse sentido, tais estratégias são opções de diálogo entre as áreas e devem compor um currículo articulado, integrado e coerente, podendo ser importantes para superar a concepção linear e fragmentada de acordo com a qual os conteúdos estão organizados no currículo: assuntos geralmente sem relação uns com os outros, muito menos com outras disciplinas (SÃO PAULO, 2007).

As sequências didáticas, que são métodos de perspectiva processual que incluem fases de planejamento, aplicação e avaliação (ZABALA, 1998), devem ser elaboradas a partir de conteúdos adequados para cumprir seus objetivos, além de apresentar alguns aspectos determinantes do processo de ensino: levantamento de conhecimentos prévios em relação ao conteúdo a fim de que os alunos possam entrar em conflito com suas concepções iniciais e, assim, buscar novos conhecimentos; apresentação de conteúdos de forma significativa e funcional, levando em conta as competências atuais dos alunos para que eles estabeleçam relações entre os novos conteúdos e seus conhecimentos prévios por meio de construções pessoais. Elas também devem permitir que o aluno adquira habilidades que o levem a ser cada vez mais autônomo em relação à sua aprendizagem (ZABALA, 1998). 
Dessa maneira, as sequências didáticas se tornam instrumentos importantes para estabelecer relações entre as diversas áreas. Ao fazer uso das atividades propostas, o professor aproxima os conteúdos da realidade dos alunos, incentiva a busca pelo conhecimento e estimula-os a formar uma visão mais global dos conteúdos que serão trabalhados (ZABALA, 1998). Além disso, elas permitem que se desenvolva um processo de reflexão por parte do professor, que consegue enxergar sua prática com um olhar mais crítico, para então poder reorganizá-la de acordo com a realidade em que atua e com as necessidades de seus alunos (SANTOS, 2008).

Tendo esse panorama como referência, o estudo aqui apresentado investigou a visão crítica de especialistas em relação a uma proposta de sequência didática que inter-relaciona as áreas de educação física e biologia.

\section{Metodologia}

Este artigo teve como origem um trabalho de pesquisa cujo objetivo principal foi elaborar uma proposta de sequência didática que integrasse as disciplinas de biologia e educação física para, então, submetê-la à análise de especialistas no assunto. A sequência foi elaborada tendo como tema a fisiologia do exercício, e foram selecionados conteúdos como: frequência cardíaca; anatomia e fisiologia do sistema circulatório; funções dos órgãos; e sistemas e doenças cardíacas relacionadas à prática de exercícios físicos.

As atividades propostas nas aulas da sequência didática eram diversificadas e variavam entre aulas práticas, aulas expositivas dialogadas, discussões e trabalhos em grupo. A problematização central foi a seguinte: como podemos relacionar atividade física com o funcionamento de nosso sistema circulatório? A intenção era relacionar as funções, as contribuições, as características e os efeitos do sistema circulatório sobre o corpo durante a prática de exercícios físicos.

Segue um resumo de cada aula proposta: ${ }^{1}$

\section{Aula 1 - 0 sistema circulatório: anatomia e fisiologia}

A partir da definição de conceitos como frequência cardíaca, frequência respiratória, componentes e principais funções do sistema circulatório, faz-se um levantamento dos conhecimentos
1. A sequência didática encontra-se disponível, na íntegra, no seguinte endereço eletrônico: <http://www.mackenzie.br/fileadmin/Graduacao/CCBS/Cursos/ Ciencias_Biologicas/2013/10_ SEM/Biblioteca_TCC_Lic/Fernanda_Lorena.pdf>. 
prévios dos alunos. Depois, por meio de desenhos, os alunos representam a disposição interna dos órgãos do sistema circulatório e, por fim, levantam hipóteses em torno da seguinte questão: o que acontece com nosso corpo quando praticamos atividades físicas?

\section{$\underline{\text { Aula } 2}$ - 0 sistema circulatório}

Em grupos, em um espaço fora da sala de aula, os alunos socializam e discutem as atividades realizadas na aula 1. Em seguida, fazem um registro e elaboram um esquema que represente a relação das funções do sistema circulatório com sua anatomia.

Aula 3 - Atividade prática: relação e importância da atividade física

Os alunos observam, na prática, as questões discutidas anteriormente sobre a relação da atividade física com a frequência cardíaca. Divididos em grupos, eles realizam diferentes tipos de exercícios físicos, observando a frequência cardíaca ao longo da atividade.

Aula 4 - Organização dos dados e discussão da aula prática

Os alunos organizam os dados coletados na atividade da aula anterior e buscam estabelecer relações com o que já foi discutido acerca da prática de atividades físicas.

Aula 5 - Conceitos 1

São realizadas atividades de definição de conceitos importantes para a compreensão do funcionamento do sistema circulatório. Além disso, os professores de biologia e de educação física promovem uma discussão sobre questões relacionadas aos conceitos.

Aula 6 - Construção de um modelo de coração

Os alunos constroem um modelo de coração com massinha de modelar, tendo oportunidade para o esclarecimento de dúvidas.

$\underline{\text { Aula } 7}$ - Frequência cardíaca: influências

Apresentação de um vídeo que aborda temas como sístole e diástole, o coração como uma bomba, nutrição, vasos sanguíneos e outros, além de discussão sobre situações-problema relativas ao assunto. 


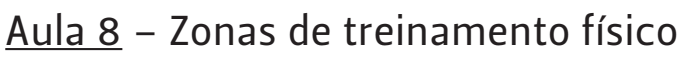

Discussão e elaboração de hipóteses relacionando as zonas de treinamento físico à frequência cardíaca nos diferentes tipos de atividade. Nessa etapa também acontece a realização de um estudo dirigido com questões sobre o tema da aula.

\section{$\underline{\text { Aula } 9}$ - Diferentes intensidades físicas}

Os alunos assistem a dois vídeos de atletas praticando dois esportes diferentes (natação e tênis de mesa, por exemplo). Em seguida, discutem sobre as zonas de treinamento físico e as diferenças de esforço entre os atletas das diferentes modalidades.

Aula 10 - Conceitos II

Os alunos relatam o que observaram em relação ao desempenho e ao estado físico dos atletas dos vídeos assistidos na aula anterior. A discussão deve abordar assuntos importantes, como a relação entre sistema respiratório e sistema cardíaco, e as influências da atividade física sobre o coração de acordo com o tipo de prática.

\section{Aula 11 - Elaboração textual}

Produção de um texto a partir de aspectos relevantes do tema discutido.

$\underline{\text { Aula } 12}$ - Doenças de coração relacionadas às praticas esportivas

Os alunos pesquisam notícias que mostrem casos de doenças cardíacas relacionadas à prática de atividades físicas, selecionam algumas para resumir e levam na aula seguinte.

Aula 13 - Apresentação e discussão dos dados coletados pelos alunos

Os alunos analisam o material coletado na aula anterior e discutem sobre como as doenças cardíacas podem prejudicar a carreira de atletas profissionais. Além disso, a discussão pode abordar o preparo de atletas profissionais e a regulamentação de eventos oficiais em relação a esse preparo.

Aula 14 - Levantamento de atividades físicas praticadas pela comunidade escolar

Os alunos realizam uma pequena pesquisa sobre as atividades físicas mais praticadas pelos funcionários da escola e pelos colegas de turma. 
Aula 15 - Análise dos dados e discussão

Organização, socialização e discussão dos dados levantados na aula anterior, buscando relacioná-los à importância da atividade física.

\section{$\underline{\text { Aula } 16}$ - Apresentação do produto final}

Os alunos elaboram um jornal com o objetivo de informar as pessoas sobre a importância da prática de atividades físicas, as relações e influências de tais atividades no sistema circulatório e possíveis doenças a esse respeito.

A sequência foi enviada para a análise de especialistas de diferentes áreas relacionadas ao tema do projeto de pesquisa: licenciatura, educação física, biologia e fisiologia. Em um primeiro momento, a intenção era submetê-la ao exame dos quatro especialistas, mas apenas recebemos a resposta de três deles: das áreas de educação física, licenciatura e biologia.

A escolha desses especialistas se deu devido à familiaridade com o tema tratado na sequência didática e à necessidade de coletar diferentes opiniões e comentários sobre a proposta, enriquecendo os resultados. 0 contato foi feito via e-mail. Juntamente com o pedido de colaboração na pesquisa foi enviado o seguinte roteiro para guiar a análise:

1) Aspectos positivos:

2) Aspectos negativos:

3) Aplicabilidade:

4) Coerência:

5) Comentários gerais:

Na leitura dos pareceres produzidos pelos especialistas, houve uma padronização dos dados coletados, de modo que foram considerados apenas os seguintes tópicos: aspectos positivos, aspectos negativos, aplicabilidade e comentários gerais. Estes foram analisados um a um a partir de pontos em comum entre os pareceres dos três avaliadores. 


\section{Resultados e discussão}

As tabelas a seguir apresentam os pareceres completos dos especialistas.

Tabela 1 - Análise do primeiro avaliador: especialista em educação física

\begin{tabular}{|c|c|c|c|}
\hline $\begin{array}{l}\text { ASPECTOS } \\
\text { POSITIVOS }\end{array}$ & $\begin{array}{l}\text { ASPECTOS } \\
\text { NEGATIVOS }\end{array}$ & APLICABILIDADE & $\begin{array}{l}\text { COMENTÁRIOS } \\
\text { GERAIS }\end{array}$ \\
\hline $\begin{array}{l}\text { Informação sobre } \\
\text { o que o aluno vai } \\
\text { aprender. }\end{array}$ & $\begin{array}{l}\text { A problematização } \\
\text { poderia ser } \\
\text { ajustada para } \\
\text { a solução de } \\
\text { problemas } \\
\text { relacionados } \\
\text { aos conteúdos } \\
\text { ensinados e a casos } \\
\text { concretos que os } \\
\text { alunos terão que } \\
\text { descobrir. }\end{array}$ & $\begin{array}{l}\text { Conteúdo muito } \\
\text { bom e que pode } \\
\text { ser aplicado. }\end{array}$ & $\begin{array}{l}\text { Identificar no } \\
\text { cronograma qual } \\
\text { professor irá } \\
\text { desenvolver a } \\
\text { atividade. }\end{array}$ \\
\hline $\begin{array}{l}\text { Informação sobre } \\
\text { o que o aluno vai } \\
\text { aprender. }\end{array}$ & $\begin{array}{l}\text { Ausência da } \\
\text { escolha de uma } \\
\text { série. }\end{array}$ & $\begin{array}{l}\text { É difícil imaginar } \\
\text { como professores } \\
\text { de biologia e de } \\
\text { educação física } \\
\text { poderiam estar } \\
\text { juntos. }\end{array}$ & $\begin{array}{l}\text { Intercalar com as } \\
\text { aulas práticas de } \\
\text { educação física. }\end{array}$ \\
\hline $\begin{array}{l}\text { Levantamento dos } \\
\text { conhecimentos } \\
\text { prévios. }\end{array}$ & $\begin{array}{l}\text { A presença do } \\
\text { professor de } \\
\text { educação física } \\
\text { em aulas teóricas } \\
\text { reduz as atividades } \\
\text { práticas. }\end{array}$ & $\begin{array}{l}\text { Disponibilizar } \\
\text { ao docente de } \\
\text { educação física o } \\
\text { material teórico e } \\
\text { as atividades feitas } \\
\text { em sala. }\end{array}$ & $\begin{array}{l}\text { Atitudes: valorizar } \\
\text { a importância da } \\
\text { atividade física } \\
\text { na manutenção } \\
\text { da saúde e da } \\
\text { qualidade de vida. }\end{array}$ \\
\hline $\begin{array}{l}\text { A finalização e a } \\
\text { avaliação permitem } \\
\text { aprimorar as } \\
\text { estratégias e } \\
\text { aproximar os } \\
\text { conteúdos dos } \\
\text { interesses dos } \\
\text { alunos. }\end{array}$ & & $\begin{array}{l}\text { Verificar o tema da } \\
\text { aula } 12 .\end{array}$ & $\begin{array}{l}\text { Incluir as } \\
\text { disciplinas inglês } \\
\text { e/ou português } \\
\text { na atividade de } \\
\text { finalização. }\end{array}$ \\
\hline \multicolumn{4}{|l|}{$\begin{array}{l}\text { Objetivos } \\
\text { adequados e } \\
\text { coerentes. }\end{array}$} \\
\hline $\begin{array}{l}\text { Atividades } \\
\text { diversificadas e } \\
\text { ricas. }\end{array}$ & & & \\
\hline
\end{tabular}


Tabela 2 - Análise do segundo avaliador: especialista em licenciatura em biologia

\begin{tabular}{|c|c|c|c|}
\hline $\begin{array}{l}\text { ASPECTOS } \\
\text { POSITIVOS }\end{array}$ & $\begin{array}{l}\text { ASPECTOS } \\
\text { NEGATIVOS }\end{array}$ & APLICABILIDADE & $\begin{array}{l}\text { COMENTÁRIOS } \\
\text { GERAIS }\end{array}$ \\
\hline $\begin{array}{l}\text { Apresentação da } \\
\text { justificativa teórica. }\end{array}$ & $\begin{array}{l}\text { Confusões na } \\
\text { definição de } \\
\text { conteúdos } \\
\text { atitudinais. }\end{array}$ & $\begin{array}{l}\text { Rever o } \\
\text { planejamento a } \\
\text { cada bimestre. }\end{array}$ & $\begin{array}{l}\text { Aula 2: pode levar } \\
\text { a conclusões } \\
\text { simplistas e } \\
\text { finalistas. }\end{array}$ \\
\hline $\begin{array}{l}\text { Etapas das aulas } \\
\text { bem explicadas no } \\
\text { texto. }\end{array}$ & $\begin{array}{l}\text { Falta a definição } \\
\text { da série em que } \\
\text { a sequência será } \\
\text { aplicada. }\end{array}$ & $\begin{array}{l}\text { Encontro semanal } \\
\text { dos professores. }\end{array}$ & $\begin{array}{l}\text { Aula 4: poderia } \\
\text { trabalhar com } \\
\text { gráfico de barras e } \\
\text { não se comentou } \\
\text { sobre a frequência } \\
\text { respiratória. }\end{array}$ \\
\hline $\begin{array}{l}\text { Sequência com } \\
\text { comandas e } \\
\text { expectativas de } \\
\text { aprendizagem bem } \\
\text { descritas. }\end{array}$ & $\begin{array}{l}\text { Nas aulas } 2 \text { e } 3, \text { não } \\
\text { é apropriado usar } \\
\text { o termo atividade } \\
\text { física de modo } \\
\text { genérico, como se } \\
\text { qualquer atividade } \\
\text { física fosse igual. }\end{array}$ & $\begin{array}{l}\text { Os horários dos } \\
\text { professores } \\
\text { muitas vezes não } \\
\text { coincidem. }\end{array}$ & \\
\hline $\begin{array}{l}\text { Valorização dos } \\
\text { registros pelos } \\
\text { alunos. }\end{array}$ & \begin{tabular}{|l|} 
Na aula 3, a \\
discussão sobre \\
veracidade da \\
ciência não cabe no \\
contexto.
\end{tabular} & $\begin{array}{l}\text { Sequência é viável } \\
\text { no aspecto da } \\
\text { infraestrutura. }\end{array}$ & $\begin{array}{l}\text { Sugestão para a } \\
\text { aula 14: a partir } \\
\text { dos pequenos } \\
\text { instrumentos } \\
\text { produzidos pelos } \\
\text { grupos, elaboração } \\
\text { coletiva de um } \\
\text { instrumento } \\
\text { geral do conjunto } \\
\text { completo de dados } \\
\text { coletados. }\end{array}$ \\
\hline $\begin{array}{l}\text { Variedade de } \\
\text { atividades. }\end{array}$ & $\begin{array}{l}\text { Na aula 7, } \\
\text { o conteúdo } \\
\text { conceitual não está } \\
\text { claro. }\end{array}$ & & $\begin{array}{l}\text { Avaliação: avaliar } \\
\text { a participação dos } \\
\text { alunos em aula. }\end{array}$ \\
\hline $\begin{array}{l}\text { Há pontos com } \\
\text { contextualização. }\end{array}$ & $\begin{array}{l}0 \text { objetivo da aula } \\
10 \text { está confuso. }\end{array}$ & & $\begin{array}{l}\text { Faltou um } \\
\text { instrumento para a } \\
\text { coleta de dados. }\end{array}$ \\
\hline $\begin{array}{l}\text { Atividade de } \\
\text { levantamento de } \\
\text { dados. }\end{array}$ & $\begin{array}{l}\text { Na aula 11, há } \\
\text { uma contradição: } \\
\text { a atividade de } \\
\text { avaliação é sem } \\
\text { contexto. }\end{array}$ & & \\
\hline \multicolumn{4}{|l|}{$\begin{array}{l}\text { Objetivos propostos } \\
\text { são atingidos. }\end{array}$} \\
\hline $\begin{array}{l}\text { As atividades } \\
\text { privilegiam as } \\
\text { construções } \\
\text { coletivas. }\end{array}$ & & & \\
\hline
\end{tabular}


continua...

\begin{tabular}{|l|l|l|l|}
\hline $\begin{array}{l}\text { As disciplinas estão } \\
\text { bem articuladas. }\end{array}$ & & & \\
\hline Trabalho a partir & & & \\
de conteúdos & & & \\
conceituais, & & & \\
procedimentais e & & & \\
atitudinais. & & & \\
\hline $\begin{array}{l}\text { Proposta de } \\
\text { avaliação coerente. }\end{array}$ & & & \\
\hline
\end{tabular}

Tabela 3 - Análise do terceiro avaliador: especialista em biologia

\begin{tabular}{|c|c|c|c|}
\hline $\begin{array}{l}\text { ASPECTOS } \\
\text { POSITIVOS }\end{array}$ & $\begin{array}{l}\text { ASPECTOS } \\
\text { NEGATIVOS }\end{array}$ & APLICABILIDADE & $\begin{array}{l}\text { COMENTÁRIOS } \\
\text { GERAIS }\end{array}$ \\
\hline $\begin{array}{l}\text { Planejamento } \\
\text { não centrado no } \\
\text { improviso. }\end{array}$ & $\begin{array}{l}\text { Muito tempo } \\
\text { é usado para } \\
\text { se chegar a } \\
\text { conclusões } \\
\text { e conceitos } \\
\text { são pouco } \\
\text { aprofundados. }\end{array}$ & $\begin{array}{l}\text { Sequência com } \\
\text { mérito para } \\
\text { aplicação. }\end{array}$ & $\begin{array}{l}\text { Falta definir uma } \\
\text { série como foco. }\end{array}$ \\
\hline $\begin{array}{l}\text { Intenções } \\
\text { declaradas e claras. }\end{array}$ & $\begin{array}{l}\text { Excesso de trabalho } \\
\text { em grupo. }\end{array}$ & $\begin{array}{l}\text { Seu grau de } \\
\text { efetividade vai } \\
\text { depender dos } \\
\text { ajustes que serão } \\
\text { feitos. }\end{array}$ & $\begin{array}{l}\text { Aula 8: seria um } \\
\text { bom momento } \\
\text { para um trabalho } \\
\text { individual. }\end{array}$ \\
\hline $\begin{array}{l}\text { Proposta } \\
\text { interdisciplinar } \\
\text { pertinente. }\end{array}$ & $\begin{array}{l}\text { Conceitos pouco } \\
\text { aprofundados. }\end{array}$ & & $\begin{array}{l}\text { Aula 12: não se } \\
\text { aprende a fazer } \\
\text { resumo em uma } \\
\text { única aula. }\end{array}$ \\
\hline $\begin{array}{l}\text { Diversidade de } \\
\text { atividades. }\end{array}$ & $\begin{array}{l}\text { Não há feedbacks } \\
\text { avaliativos. }\end{array}$ & & $\begin{array}{l}\text { Aula 13: o trecho } \\
\text { citado poderia } \\
\text { ser usado como } \\
\text { problemática } \\
\text { inicial da } \\
\text { sequência. } \\
\text { Avaliação muito } \\
\text { subjetiva e difícil } \\
\text { de se realizar. }\end{array}$ \\
\hline $\begin{array}{l}\text { Possibilita } \\
\text { reflexões e } \\
\text { contextualizações. }\end{array}$ & $\begin{array}{l}\text { A avaliação } \\
\text { apresenta aspectos } \\
\text { muito subjetivos. }\end{array}$ & & \\
\hline $\begin{array}{l}\text { Estimula a } \\
\text { discussão. }\end{array}$ & $\begin{array}{l}\text { Procedimentos } \\
\text { importantes para o } \\
\text { processo não foram } \\
\text { considerados, como } \\
\text { os conteúdos de } \\
\text { aprendizagem. }\end{array}$ & & \\
\hline $\begin{array}{l}\text { Possibilita a } \\
\text { contribuição para a } \\
\text { comunidade. }\end{array}$ & & & \\
\hline
\end{tabular}


0 primeiro grande tópico abarca os aspectos positivos identificados pelos especialistas na sequência didática.

Destacamos alguns que apareceram nas análises dos avaliadores: o levantamento de conhecimentos prévios; a diversidade e a riqueza das atividades; a informação e a boa descrição das expectativas de aprendizagem; a busca pela contextualização com a vida do aluno. Zabala (1998) aponta como um elemento importante para a construção da aprendizagem no processo de ensino o levantamento de conhecimentos prévios para que, assim, possam ser atribuídos novos significados a estruturas cognitivas elaboradas anteriormente pelos alunos.

A contextualização entre os assuntos a serem trabalhados e o cotidiano dos alunos foi outro aspecto mencionado. Os Parâmetros curriculares nacionais (BRASIL, 1998) determinam que as experiências de vida dos alunos devem ser levadas em consideração no momento do planejamento curricular, de maneira a aproximar o conteúdo visto em sala de aula e o cotidiano da turma, bem como estabelecer relações e uma compreensão mais ampla dos assuntos abordados. Como exemplo, temos a atividade de investigação sobre as atividades físicas mais praticadas pela comunidade escolar, o que foi ressaltado pela segunda avaliadora.

Segundo as orientações curriculares para o ensino de ciências (SÃO PAULO, 2007), as sequências didáticas devem apresentar diversas atividades que permitam aos alunos fazer relações entre informações e conteúdos desconexos e, a partir dessas atividades, desenvolver uma aprendizagem mais ampla e completa. Da mesma forma, a informação sobre os objetivos e as expectativas de aprendizagem das atividades propostas também é parte do processo da organização curricular, devendo ser bem definida para que se alcance sucesso em seu desenvolvimento.

Em relação aos aspectos negativos, todos os avaliadores apontaram a falta da definição da série em que a sequência será aplicada. Consideramos que a correção desse aspecto é importante, pois, de acordo com as orientações curriculares para o ensino de ciências (SÃO PAULO, 2007), a organização curricular se apresenta como uma ferramenta de organização e planejamento dos professores. Sendo assim, faz-se necessário definir a série em que aquelas atividades serão aplicadas para que os objetivos e as expectativas de aprendizagem sejam elaborados de maneira coerente com o perfil dos alunos que irão realizá-las.

0 terceiro tópico avaliado pelos especialistas foi a aplicabilidade da sequência didática. Quanto a esse aspecto, dois dos avaliadores 
mencionaram uma provável dificuldade na aplicação da sequência, uma vez que a maioria das escolas dificilmente poderia garantir um trabalho interdisciplinar dos professores dessas áreas devido à falta de tempo e à distribuição do horário desses profissionais. Tal crítica já era esperada tendo em vista o panorama atual da organização curricular, que é fragmentada (ZABALA, 2002) e não permite desenvolver um projeto interdisciplinar.

Os especialistas também ressaltaram que a sequência tem mérito de aplicação, tanto em relação ao seu conteúdo considerando-se o levantamento de conhecimentos prévios em algumas atividades -, quanto em relação à infraestrutura necessária. Entendemos que esse é um aspecto importante no que concerne à aplicabilidade da sequência, pois, segundo Zabala (1998), a aprendizagem se configura a partir de uma construção pessoal, processo em que o aluno contribui com seus conhecimentos prévios. Sendo assim, o levantamento desses conhecimentos é fundamental para que se elaborem e se atinjam com sucesso os objetivos e as expectativas de aprendizagem da sequência didática.

Os avaliadores consideraram a sequência aplicável desde que os aspectos negativos apontados sejam corrigidos. Nesse sentido, enxergamos claramente a importância do exercício reflexivo na prática docente exaltada por Nóvoa (1997): a reflexão na ação, em que o professor reflete sobre uma aula ou atividade que aplicou, podendo identificar lacunas em sua prática e aspectos que precisam de aprimoramento.

Por fim, o último tópico foi relativo a comentários gerais. Nele obtivemos uma grande diversidade de comentários, já que o item permitia que os avaliadores se manifestassem mais livremente sobre a sequência didática. 0 primeiro deles mencionou a necessidade de o cronograma intercalar mais aulas práticas de educação física e especificar qual professor realizaria cada atividade. 0 segundo comentou a respeito da avaliação, entendendo que é necessário haver uma maior ênfase na participação dos alunos durante as aulas e uma maior valorização de tal participação no momento de avaliar os alunos. Hoffmann (2005) salienta que a avaliação é um movimento de reflexão: quando os alunos realizam suas tarefas, eles refletem sobre suas ideias prévias, de modo que uma atividade complementa a outra. Assim, ao considerarmos mais a participação dos alunos - suas manifestações, discussões de ideias e argumentações -, estamos fazendo uma avaliação mais justa, considerando a reciprocidade intelectual que a avaliação permite desenvolver. 
0 terceiro avaliador comentou sobre o excesso de trabalhos em grupo e sentiu falta de momentos para que o aluno se concentre em seu processo de ensino. Nesse sentido, Hernández (1998) argumenta que os alunos devem ser capazes de elaborar construções pessoais sobre o conteúdo ensinado e que o trabalho em grupo pode atrapalhar esse processo individual, dificultando a tomada de consciência por parte de cada aluno quanto ao seu próprio percurso.

O exercício de reflexão sobre a sequência didática elaborada tornou-se extremamente importante para a concretização desta análise e para a conclusão do trabalho como um todo. Conforme assevera Santos (2008), a reflexão se faz importante no processo de ensino-aprendizagem, pois é a partir dela que o docente consegue repensar suas práticas e, assim, aprimorar cada vez mais seu planejamento, visando atender às expectativas e necessidades dos alunos.

\section{Considerações finais}

Atualmente, as escolas adotam um currículo fragmentado e fundado em conteúdos desconexos que fazem pouco ou nenhum sentido para os alunos. A organização curricular deve acontecer baseada nas contribuições de cada disciplina para o processo de ensino-aprendizagem. Ou seja, os conteúdos devem estar organizados de forma que uma disciplina complemente a outra no sentido mais global possível, possibilitando o estabelecimento de vínculos e relações (SÃO PAULO, 2007).

Com base em uma abordagem interacionista, consideramos que o objetivo do ensinar é formar pessoas íntegras e aptas a compreender a sociedade em que vivem, sendo capazes de nela intervir a fim de melhorá-la (ZABALA, 2002). Para que tal objetivo seja atingido, o currículo precisa estar organizado de maneira desfragmentada, não linear e articulada, evitando a compactação dos conteúdos em disciplinas, uma vez que isso dificulta uma compreensão mais global, por parte dos alunos, acerca dos temas trabalhados.

Considerando que o objetivo norteador desta pesquisa foi a elaboração de uma sequência didática que buscasse a integração entre as disciplinas de biologia e educação física, bem como a diminuição da fragmentação do currículo escolar, tendo a fisiologia do exercício como tema principal, podemos dizer que nosso propósito foi atingido. Os conteúdos trabalhados abrem 
oportunidades de relação com ambas as disciplinas e, assim, possibilitam um processo de ensino menos fragmentado e muito mais integrado se comparado ao que vemos tradicionalmente.

Para uma maior compreensão da abrangência e da eficiência da sequência didática proposta, daremos continuidade ao trabalho por meio da aplicação da sequência em outro projeto de pesquisa, em que pretendemos coletar os resultados e analisar a eficiência do instrumento quanto à integração das disciplinas envolvidas, bem como sua colaboração para o aprimoramento do processo de ensino.

0 trabalho com a sequência didática é importante, pois permite um exercício reflexivo do professor sobre sua própria prática na sala de aula. Quando propomos um projeto e este é analisado por especialistas de diversas áreas relacionadas ao tema, a devolutiva é muito rica em sugestões e contribuições para o aprimoramento das atividades. Sendo assim, ao refletirmos sobre a sequência didática que elaboramos, acabamos por refletir sobre nossas ideias, concepções, propostas e práticas, o que enriquece nosso fazer docente. Tendo em vista que o trabalho como um todo terá continuidade, pensar sobre ele e sobre o que pode ser melhorado é essencial para que nosso projeto se torne o melhor possível em sua aplicação e traga resultados significativos e de qualidade para a aprendizagem dos alunos.

\section{REFERÊNCIAS}

ALVES. Rubem. O senso comum e a ciência I. In:

Filosofia da ciência. São Paulo: Edições Loyola, 2000. p. 9-21.

BRASIL. Secretaria de Educação Fundamental. Parâmetros curriculares nacionais $5^{a}$ a $8^{a}$ séries. Brasília: MEC/SEF, 1998. Disponível em: <http://portal.mec.gov.br/index. php? view=article\&id=12657>. Acesso em 10 abr. 2013.

HERNÁNDEZ, Fernando. Transgressão e mudança na educação: os projetos de trabalho. Porto Alegre: Artmed, 1998.

HERNÁNDEZ, Fernando; VENTURA, Montserrat. A organização do currículo por projetos de trabalho: o conhecimento é um caleidoscópio. Porto Alegre: Artmed, 1998. 
HOFFMANN, Jussara. Imprecisões da terminologia: o significado do testar e do medir. In: Mito e desafio: uma perspectiva construtivista. 36. ed. Porto Alegre: Mediação Ed., 2005. p. 43-63.

NÓVoA, Antônio. Formação de professores e profissão docente. In: Os professores e sua formação. 3. ed. Lisboa: Dom Quixote, 1997. p. 15-34.

SANTOS, Lucimara. Mudanças na prática docente: um desafio da formação continuada de professores polivalentes para ensinar matemática. Dissertação (Mestrado Profissional) Pontifícia Universidade Católica, São Paulo, 2008.

SÃO PAULO. Secretaria Municipal de Educação. Orientações curriculares e proposição de expectativas de aprendizagem para o ensino fundamental: ciclo Il: ciências naturais. São Paulo: SME/DOT, 2007. Disponível em: <http://portalsme. prefeitura.sp.gov.br/Documentos/BibliPed/EnsFundMedio/ Cicloll/OrientacpesCurriculares_proposicao_expectativas_ de_aprendizagem_EnsFundll_Cie.pdf>. Acesso em: 10 abr. 2012.

ZABALA, Antoni. As sequências didáticas e as sequências de conteúdo. In: A prática educativa: como ensinar. Porto Alegre: Artmed, 1998. p. 53-87.

Organização dos conteúdos de aprendizagem. In: Enfoque globalizador e pensamento complexo: uma proposta para o currículo escolar. Porto Alegre: Artmed, 2002. p. $15-42$.

Recebido em: 20/02/2013

Revisado em: 28/03/2013

Aprovado em: 01/04/2013 